\title{
Observational study on dietary patterns in pregnancy
}

\author{
Studiu observațional privind caracterizarea tiparelor alimentare în sarcină \\ Alina Delia POPA ${ }^{1}$, Lavinia CABA ${ }^{2}$, Armand ENACHE ${ }^{1}$, Carmen MIHALACHE ${ }^{3}$, Ileana ANTOHE ${ }^{1}$ \\ ${ }^{1}$ Departamentul Nursing, Facultatea of Medicină, \\ Universitatea de Medicină şi Farmacie „Grigore T. Popa“, Iași, România \\ ${ }^{2}$ Departamentul Genetică, Facultatea of Medicină, \\ Universitatea de Medicină şi Farmacie „Grigore T. Popa“, Iași, România \\ ${ }^{3}$ Departamentul Chirurgie, Facultatea of Medicină, \\ Universitatea de Medicină şi Farmacie „Grigore T. Popa“, Iași, România
}

\begin{abstract}
Pregnancy nutrition influences the short-term maternal and fetal prognosis, but also the state of health in the future, an inadequate diet being associated with the risk of chronic diseases in adulthood. The purpose of the study is to characterize the diet of a group of pregnant women in Iasi county in terms of macronutrient intake, but also food patterns.

Material and methods. An observational study was performed on a sample of 400 pregnant women which consisted in the application of a validated food frequency questionnaire. The foods consumed were grouped into categories: meat, eggs, fish, milk and dairy products, bread and cereals, vegetables, fruits, soups, seeds and oilseeds, sweets and fast food. Factor analysis (main component analysis method) was used for the analysis of food patterns.

Results. The average energy intake in the studied group was 2197 kcal/day (95\% CI: 2139.57-2255.74). The intake of macronutrients during pregnancy was $86.01 \mathrm{~g}$ protein (95\% CI: 83.64-88.39), $76.97 \mathrm{~g}$ lipids (95\% CI: 74.59-79.35) and 297.12 g carbohydrate (95\% Cl: 287.86-306.38). We identified 3 dietary patterns that explained $43.01 \%$ of the variation of consumption behaviour: healthy consumption, consisting of a diet rich in soups, fruits, eggs and vegetables; traditional consumption, which has high consumption values for bread, dairy, meat, fat and unhealthy consumption rich in the intake of sweets, fast food and seeds.

Conclusions. The identified food patterns draw attention to the existence of a category at risk of developing pathology related to inadequate nutrition in pregnancy.
\end{abstract}

Keywords: pregnancy, FFQ, dietary patterns

\section{REZUMAT}

Alimentația în sarcină infuențează prognosticul matern și fetal pe termen scurt, dar și starea de sănătate în viitor, o dietă necorespunzătoare asociindu-se cu riscul bolilor cronice la vârsta adultă. Scopul studiului constă caracterizarea dietei unui lot de gravide din județul Iași din punctul de vedere al aportului de macronutrienți, dar și al tiparelor alimentare.

Material și metode. S-a realizat un studiu observațional pe un eșantion de 400 gravide, care a constat în aplicarea unui chestionar validat de frecvență alimentară. Alimentele consumate s-au grupat în categorii: 
carne, ouă, pește, lapte și derivate, pâine și cereale, legume, fructe, supe, semințe și oleaginoase, dulciuri și alimente fastfood. Pentru analiza tiparelor alimentare, s-a recurs la analiza factorială (metoda de analiză a componentelor principale).

Rezultate. Aportul mediu energetic în lotul studiat a fost de $2197 \mathrm{kcal} / z i$ (95\%CI: 2139,57-2255,74). Aportul de macronutrienți în timpul sarcinii a fost de 86,01 g proteine (95\% CI: 83,64-88,39), 76,97 g lipide (95\% CI: 74,59-79,35) şi 297,12 g glucide (95\%CI: 287,86-306,38). S-au identificat 3 tipare alimentare care au explicat 43,01\% din variația comportamentului de consum: consum sănătos, constând în alimentația bogată în ciorbe, fructe, ouă şi legume; consum tradițional, la care se înregistrează valori mari de consum pentru pâine, lactate, carne, grăsimi și consum nesănătos bogat în aportul de dulciuri, fast-food şi semințe.

Concluzii. Tiparele alimentare identificate atrag atenția asupra existenței unei categorii la risc de a dezvolta patologie legată o nutriție inadecvată în sarcină.

Cuvinte cheie: sarcină, chestionar frecvența alimentară, tipare alimentare

\section{INTRODUCERE}

Necesitățile nutritive cresc în sarcină. O cantitate adecvată de nutrienți este importantă pentru creșterea și dezvoltarea fetală și pentru susținerea modificărilor materne. Programarea metabolică este veriga asocierii dintre malnutriția în perioada intrauterină și dezvoltarea bolilor cronice la vârsta adultă. Supraalimentația, supraponderea și hipertrigliceridemia maternă s-a asociat cu creșterea greutății la naștere, a adipozității, a citokinelor inflamatorii și leptinei la copii. Acestea determină hiperfagie, rezistență la insulină și risc pentru diabet zaharat și obezitate.

Ghidul de practică pentru medicii de familie „Îngrijiri prenatale de rutină în sarcina cu risc scăzut" recomandă pentru majoritatea gravidelor o dietă echilibrată, cu un aport energetic de aproximativ $2300 \mathrm{kcal}$ zilnic, menționând că restricțiile dietetice la gravidele supraponderale sau cu o creștere excesivă a greutății în timpul sarcinii nu sunt benefice și pot fi chiar dăunătoare dezvoltării fătului [1].

Scopul acestui studiu este de a realiza o caracterizare descriptivă a dietei unui eșantion de gravide din punctul de vedere al aportului de nutrienți și al tiparelor alimentare cel mai frecvent întâlnite.

\section{MATERIAL ŞI METODE}

Am efectuat un studiu transversal pe un eșantion care a inclus un număr de 400 de gravide internate la Spitalul Clinic de Obstetrică și Ginecologie „Cuza-Vodă“ din Iași, în perioada august-septembrie 2015. Criteriile de excludere au fost sarcina gemelară, refuzul pacientei, patologia obstetricală. Colectarea informațiilor s-a realizat prin interviu direct și înregistrarea acestora într-o fișă individuală care a fost completată prin interviu direct. Întrebările din această fișă s-au referit la date demografice (vârsta, mediul de proveniență, starea civilă, nivelul de școlarizare); patologia gravidei în prezent și în antecedente; utilizarea consultației prena- tale. Pentru evaluarea aportului alimentar, s-a utilizat un chestionar de frecvență alimentară semicantitativ, validat anterior [2], care a fost completat prin interviu direct. Prin aplicarea acestui chestionar s-a obținut aportul caloric de macronutrienți, calciu, magneziu, fibre alimentare și colesterol. Alimentele consumate s-au grupat în categorii: carne, ouă, pește, lapte și derivate, pâine și cereale, legume, fructe, supe, semințe și oleaginoase, dulciuri și alimente fastfood.

Prelucrarea statistică s-a efectuat folosind programul SPSS12.0, folosind teste descriptive pentru caracterizarea generală a dietei. Pentru identificarea patternurilor alimentare s-a utilizat analiza factorială folosind metoda de analiză a componentelor principale, cu metoda de rotație Varimax.

Studiul s-a efectuat cu aprobarea Spitalului de Obstetrică-Ginecologie „Cuza-Vodă“ Iași, după avizarea de către Comisia de Bioetică a Universității de Medicină și Farmacie „Gr.T. Popa“ Iași.

\section{REZULTATE}

În lotul studiat, ponderea femeilor din mediul rural a fost de $45,8 \%$, iar a celor din mediul urban de $54,3 \%$. Vârsta medie în lotul studiat a fost de 27,53 ani, ponderea cea mai mare având-o gravidele cu vârsta între 19 și 30 de ani. Majoritatea gravidelor (96\%) au beneficiat de îngrijiri primare de sănătate. Cele mai multe mame (81\%) s-au prezentat la prima consultație prenatală la medicul de familie în primul trimestru de sarcină (Tabelul 1)

Aportul mediu energetic în lotul studiat a fost de $2197 \mathrm{kcal} / \mathrm{zi}$ (95\%Cl: 2139,57-2255,74). Aportul de macronutrienți în timpul sarcinii, în eșantionul celor 400 de gravide evaluate, a fost de $86,01 \mathrm{~g}$ proteine $(95 \% \mathrm{Cl}$ : 83,64-88,39), 76,97 g lipide (95\%Cl: 74,59-79,35) și 297,12 g glucide $(95 \% \mathrm{Cl}: 287,86-306,38)$. Din punct de vedere al distribuției macronutrienților, ca procent din aportul energetic, am observat o medie a proporției proteinelor în rația calorică de 15,79\% (95\%Cl: 15,55- 
TABEL 1. Caracteristici sociodemografice ale participantelor

\begin{tabular}{|c|c|c|c|}
\hline & & $\mathrm{Nr}$ & $\%$ \\
\hline Mediul de proveniență & Urban & 217 & 54,3 \\
\hline & Rural & 183 & 45,8 \\
\hline Vârsta & $<20$ & 356 & 89,0 \\
\hline & $\geq 20$ & 44 & 11,0 \\
\hline Nivel de școlarizare & $5-8$ & 86 & 21,5 \\
\hline & $9-12$ & 162 & 40,5 \\
\hline & $>12$ & 136 & 34,0 \\
\hline & Căsătorită & 323 & 80,8 \\
\hline Starea civilă & Necăsătorită & 77 & 19,2 \\
\hline Sarcina planificată & Da & 359 & 89,8 \\
\hline & Nu & 40 & 10,0 \\
\hline
\end{tabular}

$16,03)$, a lipidelor de $31,69 \%$ (95\% Cl: 31,11-32,28), iar a glucidelor de $53,75 \%(95 \% \mathrm{Cl}: 53,09-54,42)$, corespunzător unei nutriții echilibrate din punct de vedere al aportului de nutrienți. Am remarcat un consum mediu mai scăzut de fibre $(12,92 \mathrm{~g} ; 95 \% \mathrm{Cl}: 12,25-13,59)$, decât cel recomandat în sarcină ( $28 \mathrm{~g} / \mathrm{zi})$. Aportul mediu de colesterol a fost de 383,83 mg/zi $(95 \% \mathrm{Cl} 359,39$ $410,27)$. S-a remarcat un consum mai redus de fier și calciu, provenind din dietă, decât cel recomandat (Tabelul 2). Contribuția fierului din dietă a fost în medie de 12,98 mg/zi (95\%Cl: 12,41-13,55), iar cea realizată prin suplimentarea cu preparate de fier și de multiminerale a fost de $37,95 \mathrm{mg} / \mathrm{zi}(95 \% \mathrm{Cl}$ : 35,68-40,21), rezultând un aport mediu total de $43,43 \mathrm{mg} / \mathrm{zi}(95 \% \mathrm{Cl} 40,89$ $45,76)$. Aportul de calciu din alimentație a fost în medie de $757,22 \mathrm{mg} / z i$ (95\%Cl: 722,45-791,99), iar cel realizat prin suplimentarea cu preparate de calciu și multiminerale de $90,49 \mathrm{mg} / \mathrm{zi}(95 \% \mathrm{Cl}: 83,62-97,36)$, observânduse un consum mediu zilnic total de $826,17 \mathrm{mg}(95 \% \mathrm{Cl}$ : 790,24-862,09). Aportul de magneziu din dietă a fost în medie de 263,66 mg/zi (95\%Cl: 255,44-271,89), cel realizat prin suplimentare cu multiminerale de $48,04 \mathrm{mg} /$ zi (95\%Cl: 45,60-50,47), iar cel total $296,48 \mathrm{mg} / \mathrm{zi}$ (95\%Cl: 287,48-305,21) (Tabelul 2).

Ponderea în aportul de fier realizată prin suplimentare a fost de $55,75 \%$, fiind determinată de administrarea de preparate de fier, dar și de combinații de vitamine și minerale. Ponderea aportului de calciu $(11,36 \%)$ și magneziu $(15,94 \%)$ adusă prin administrarea suplimentelor alimentare a fost mai redusă (Tabelul 3).

Pentru identificarea tiparelor alimentare, s-a realizat analiza factorială a datelor culese prin chestionarul de frecvență alimentară, valoarea coeficientului KaiserMeyer-Olkin de 0,602, indicând adecvarea mărimii eșantionului ales pentru acest tip de analiză. Am considerat ca variabile care contribuie la formarea componentelor acele variabile care au un coeficient de corelație mai mare de 0,3 . Au fost alese 3 componente pentru a explica variația comportamentului de consum a respondenților, deoarece acestea explică, împreună, $43,015 \%$ din variația totală. Denumirea componentelor

TABEL 2. Aportul de nutrienți în sarcină - caracterizare descriptivă

\begin{tabular}{|l|c|c|c|c|c|c|c|c|}
\hline Variabile & Media & $\mathbf{- 9 5 \%}$ & $\mathbf{+ 9 5 \%}$ & Mediana & Minim & Maxim & $\boldsymbol{\sigma}$ & Er, std. \\
\hline Calorii & 2197,65 & 2139,57 & 2255,74 & 2119,98 & 1168,64 & 4729,40 & 590,93 & 29,55 \\
\hline Proteine & 86,01 & 83,64 & 88,39 & 84,25 & 31,93 & 223,69 & 24,15 & 1,21 \\
\hline Lipide & 76,97 & 74,59 & 79,35 & 72,49 & 14,23 & 197,00 & 24,19 & 1,21 \\
\hline Glucide & 297,12 & 287,86 & 306,38 & 284,69 & 130,13 & 655,74 & 94,21 & 4,71 \\
\hline Proteine\% & 15,79 & 15,55 & 16,03 & 15,54 & 9,18 & 25,18 & 2,49 & 0,12 \\
\hline Lipide\% & 31,69 & 31,11 & 32,28 & 31,95 & 9,82 & 53,24 & 5,95 & 0,30 \\
\hline Glucide \% & 53,75 & 53,09 & 54,42 & 53,73 & 33,10 & 74,63 & 6,79 & 0,34 \\
\hline Fibre & 12,92 & 12,25 & 13,59 & 11,74 & 1,86 & 46,70 & 6,82 & 0,34 \\
\hline Colesterol & 384,83 & 359,39 & 410,27 & 322,90 & 17,45 & 1537,12 & 258,83 & 12,94 \\
\hline Fe dietă & 12,98 & 12,41 & 13,55 & 11,89 & 4,27 & 56,85 & 5,78 & 0,29 \\
\hline Fe supl. & 37,95 & 35,68 & 40,21 & 38,57 & 6,43 & 96,43 & 20,56 & 1,15 \\
\hline Fe total & 43,32 & 40,89 & 45,76 & 40,99 & 4,27 & 115,19 & 24,72 & 1,24 \\
\hline Ca dietă & 757,22 & 722,45 & 791,99 & 705,75 & 149,89 & 2213,08 & 353,30 & 17,69 \\
\hline Ca supl. & 90,49 & 83,62 & 97,36 & 80,36 & 13,39 & 308,04 & 60,86 & 3,49 \\
\hline Ca total & 826,17 & 790,24 & 862,09 & 772,06 & 152,96 & 2306,83 & 365,05 & 18,28 \\
\hline Mg dietă & 263,66 & 255,44 & 271,89 & 251,49 & 98,07 & 654,81 & 83,59 & 4,18 \\
\hline Mg total & 296,48 & 287,74 & 305,21 & 284,07 & 98,07 & 729,81 & 88,75 & 4,44 \\
\hline
\end{tabular}

TABEL 3. Aportul de micronutrienți provenind din suplimentele alimentare

\begin{tabular}{|l|l|l|l|l|l|l|l|l|}
\hline Variabile & Media & $\mathbf{- 9 5 \%}$ & $\mathbf{+ 9 5 \%}$ & Mediana & Minim & Maxim & $\boldsymbol{\sigma}$ & Er. std. \\
\hline Fe supl. \% & 55,75 & 54,07 & 57,43 & 57,82 & 12,97 & 100,00 & 17,08 & 0,85 \\
\hline Ca supl. \% & 11,36 & 10,52 & 12,20 & 8,99 & 1,43 & 46,79 & 7,47 & 0,43 \\
\hline Mg supl.\% & 15,94 & 15,12 & 16,77 & 16,43 & 2,68 & 36,77 & 6,88 & 0,42 \\
\hline
\end{tabular}


se dă în funcție de variabilele care contribuie la formarea acestora (Tabelul 4, figura 1). De exemplu, componenta 1 ar putea fi denumită consum sănătos, componenta 2 ar putea fi denumită consum tradițional de alimente, iar componenta 3 ar putea fi numită consum nesănătos de alimente. Pentru componenta 1 , consum sănătos, se înregistrează valori mari ale consumului pentru ciorbe, fructe, ouă și legume. Pentru componenta 2, consum tradițional, se înregistrează valori mari de consum pentru pâine, lactate, carne, grăsimi. Pentru componenta 3 , consum nesănătos, se înregistrează valori ridicate pentru consumul de dulciuri, fastfood și semințe.

TABEL 4. Tipare ale comportamentului alimentar identificate

\begin{tabular}{|l|r|r|r|}
\hline \multirow{2}{*}{} & \multicolumn{3}{|c|}{ Component } \\
\cline { 2 - 4 } & 1 & \multicolumn{1}{c|}{2} & \multicolumn{1}{c|}{3} \\
\hline Pâine şi cereale & & 0,399 & 0,316 \\
\hline Lactate & & 0,588 & \\
\hline Grăsimi & & 0,684 & \\
\hline Carne & & 0,602 & \\
\hline Peşte & 0,420 & & 0,337 \\
\hline Ouă & 0,667 & & \\
\hline Legume & 0,702 & & \\
\hline Ciorbe & 0,711 & & 0,303 \\
\hline Fructe & & 0,339 & 0,652 \\
\hline Oleaginoase & & & 0,687 \\
\hline Fast-food & & & \\
\hline Dulciuri, răcoritoare & & & \\
\hline
\end{tabular}

\section{DISCUŢII}

Am ales FFQ în studiul nostru pentru a evalua aportul alimentar, deoarece permite o estimare retrospectivă a dietei. Ca urmare a modificărilor fiziologice mater- ne și fetale cerințele nutriționale cresc în sarcină [3], iar modificări ale dietei sunt necesare și în cadrul populațiilor cu un regim alimentar echilibrat [4].

Ghidul de practică pentru medicii de familie „,̂ngrijiri prenatale de rutină în sarcina cu risc scăzut" recomandă pentru majoritatea gravidelor o dietă echilibrată, cu un aport energetic de aproximativ 2300 kcal zilnic, menționând că restricțiiile dietetice la gravidele supraponderale sau cu o creștere excesivă a greutății în timpul sarcinii nu sunt benefice și pot fi chiar dăunătoare dezvoltării fătului [1]. Aportul mediu energetic în lotul studiat a fost de $2197 \mathrm{kcal}(95 \% \mathrm{Cl}$ : 2139,57-2255,74), mai redus decât cel recomandat în ghidul pentru medicii de familie. Aportul caloric al femeilor din lotul studiat de noi a fost mai redus decât cel al gravidelor care au fost evaluate în studii din Anglia (2452,22 kcal/zi) [5], Egipt (2700 kcal/zi) [6], Portugalia (2393 kcal/zi) [7] și China (2331 kcal/zi) [8], dar mai mare ca al celor din studii efectuate în Finlanda (2173 kcal/zi) [9] și SUA (2139 kcal/zi) [10].

Alte recomandări ale ghidului de practică pentru medicii de familie se referă la creșterea aportului de nutrienți pe durata sarcinii, în special de proteine, calciu și acid folic [1].

Aportul zilnic de macronutrienți în timpul sarcinii, în eșantionul celor 400 de participante studiate de noi, a fost de 86,01 g de proteine, 76,97 g lipide și 297,12 g glucide. Din punctul de vedere al aportului de macronutrienți, exprimat ca procent din aportul energetic, am observat o proporție medie a proteinelor în rația calorică de $15,79 \%$, a lipidelor de $31,69 \%$, iar a glucidelor de 53,75\%. Aportul zilnic de lipide în eșantionul studiat de noi a fost mai scăzut ca cel rezultat în studii efectuate în Anglia (70,4 g [5]; 83,5 g [11]), Finlanda (81 g) [9], SUA (79 g) [10], dar mai mare ca cel raportat într-un studiu din China (57 g) [8].

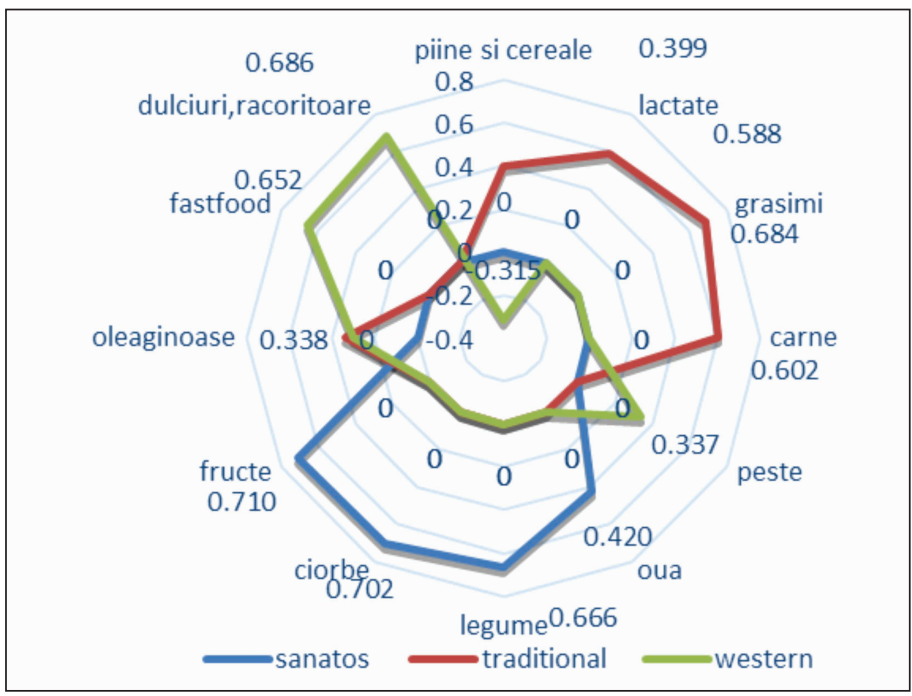

FIGURA 1. Tipare alimentare în sarcină - reprezentare grafică 
În lotul nostru, aportul de glucide a fost mai mare ca acela din studiile efectuate de Mouratidou [5] pe o cohortă din Sheffield $(217 \mathrm{~g} / \mathrm{zi})$, de Erkkola în Finlanda (285 g/zi) [9], de Baer [10] în SUA (280 g/zi), dar mai redus ca acela din studiul efectuat în China de Cheng [8], pe un eșantion de gravide din mediul rural $(391 \mathrm{~g} / \mathrm{zi})$. Într-un studiu realizat în Marea Britanie, aportul de glucide a fost de $223 \mathrm{~g} / \mathrm{zi}$, reprezentând 50\% din totalul caloric. Într-un alt studiu s-a constatat că proporția glucidelor din aportul alimentar al femeilor gravide a variat $55-59 \%$, în funcție de starea de nutriție anterioară [11]. Potrivit unui studiu efectuat la Rio de Janeiro, consumul mediu de glucide a fost de $496 \mathrm{~g} / \mathrm{zi}$, reprezentând $65 \%$ din aportul energetic total, proporții diferite de cele evaluate în studiul nostru (53,73\%) [12]. Aportul de proteine a fost mai mare în eșantionul analizat de noi decât cel din alte studii din Europa și SUA, care au inclus femei gravide și în care a variat între 63,4 și $83,5 \mathrm{~g} / \mathrm{zi}$, dar mai redus ca cel raportat într-un studiu efectuat în Egipt $(91 \mathrm{~g} / \mathrm{zi})$ [6]. Aceste proporții sunt influențate de variabilitatea obiceiurilor alimentare din diferite populații.

În studiul nostru, am observat un aport scăzut de fibre, 12,92 g/zi (95\%Cl: 12,25-13,59), în sarcină recomandându-se un aport de $28 \mathrm{~g} / \mathrm{zi}$. Un aport mai redus de fibre decât cel recomandat s-a constatat și la gravide din alte țări europene (12,4-19,4 g/zi) [5-7].

Aportul de fier din dietă în eșantionul studiat de noi a fost în medie de 12,98 mg/zi (95\%Cl: 12,41-13,55). Aportul de fier realizat prin suplimentarea cu preparate de fier și de multiminerale a fost de $37,95 \mathrm{mg} / \mathrm{zi}(95 \% \mathrm{Cl}$ : $35,68-40,21)$, rezultând un aport mediu total de fier de $43,43 \mathrm{mg} / \mathrm{zi}(95 \% \mathrm{Cl}: 40,89-45,76)$. Studiile efectuate au evidențiat că aportul zilnic de fier este în general mai redus ca cel recomandat (10,7 mg Denguezli; 11,4 mg Erkkola; 10,2 mg Mouratidou, 10,4 mg ALPSAC, Pinto 16 mg; 23,2 mg Cheng), considerându-se că necesitățile crescute din sarcină nu pot fi acoperite numai din surse alimentare $[5,7,8,9,11]$. Cu toate acestea, într-un studiu efectuat de Baer [10] în SUA, aportul de fier raportat a fost de $55 \mathrm{mg} / \mathrm{zi}$, posibil ca rezultat al fortifierii alimentelor.
În lotul nostru, aportul de calciu din alimentație a fost în medie de 757,22 mg/zi (95\%Cl: 722,45-791,99), iar cel realizat prin suplimentarea cu preparate de calciu și multiminerale de 90,49 mg/zi (95\%Cl: 83,62$97,36)$, observându-se un aport mediu zilnic total al gravidelor studiate de $826,17 \mathrm{mg} / \mathrm{zi}(95 \% \mathrm{Cl}$ : 790,24$862,09)$. Aportul mediu de calciu a fost mai redus decât cel recomandat în sarcină (1000 mg/zi). Date raportate în alte studii estimează un aport din surse alimentare mai scăzut decât cel recomandat în Anglia (692 mg, [5]; $953 \mathrm{mg}$ ALPSAC [11]), China (453 mg) [8], Egipt (557,3 $\mathrm{mg} / \mathrm{zi}$ [ [6] și mai mare decât cel recomandat în Finlanda (1342 mg) [9] și SUA (1320 mg) [10].

Tipurile de patternuri alimentare identificate în studii observaționale au fost în raport cu ponderea macronutrienților în dietă, observându-se o bună corelație cu prognosticul matern (riscul apariției diabetului gestațional) sau fetal (macrosomia fetală) [14]. În eșantionul analizat, s-au identificat trei tipare alimentare (tradițional, sănătos și fast-food), care explică $43 \%$ din variația aportului alimentar. O metaanaliză recentă, a unui număr de 35 studii, a concluzionat identificarea în majoritatea studiilor observaționale efectuate la gravide a două tipuri de tipare alimentare - sănătos, care constă într-o alimentație bogată în cereale integrale, fructe, legume și carne slabă, și nesănătos, adică o alimentație bogată în carne procesată, alimente bogate în lipide și glucide rafinate. Alimentația nesănătoasă s-a asociat cu creșterea riscului de naștere prematură sau a unor nou-născuți cu greutate mică la naștere [14].

\section{CONCLUZII}

Analiza efectuată evidențiază un aport echilibrat de macronutrienți în cursul sarcinii, dar un aport redus de fier, calciu și magneziu adus de dietă, ceea ce întărește rolul supravegherii nutriționale în sarcină și al unei educații privind comportamentul prosanogen. Patternurile alimentare identificate atrag atenția asupra existenței unei categorii la risc de a dezvolta patologie legată o nutriție inadecvată în sarcină.

\section{BIBLIOGRAFIE}

1. Centrul Naţional de Studii pentru Medicina Familiei. Îngrijiiri prenatale de rutină în sarcina cu risc scăzut. Ghid de practică pentru medicii de familie, Ed. Infomedica, laşi, 2005:48-59.

2. Popa AD, Niţă O, Popescu RM, Graur M. Validity and reproductibility of a food frequency Questionnaire designed to characterize the diet of women of childbearing age. RJDNMD. 2011 Sep;18(3):217-225.
3. Lachance PA. International perspective: basis, need, and application of recommended dietary allowances. Nutr Rev. 1998 Apr;56(4 Pt 2):S2-4.

4. Anderson AS. Symposium on ,nutritional adaptation to pregnancy and lactation'. Pregnancy as a time for dietary change? Proc Nutr Soc. 2001 Nov;60(4):497-504.

5. Mouratidou T, Ford F, Prountzou F, Fraser R. Dietary assessment of a population of pregnant women in Sheffield, UK. Br J Nutr. 2006 Nov;96(5):929-935.

6. Denguezli W, Faleh R, Hajjaji A, Saidani Z, Letaief M, Haddad A, Laajili H, Sakouhi M. Alimentation maternelle et poids foetal: rôle des oligoéléments et vitamines [Maternal nutrition as a determinant of fetal weight: role of trace elements and vitamins]. $J$ Gynecol Obstet Biol Reprod (Paris). 2007 Sep;36(5):473-478. 
7. Pinto $\mathrm{E}$, Barros $\mathrm{H}$, dos Santos Silva I. Dietary intake and nutritional adequacy prior to conception and during pregnancy: a follow-up study in the north of Portugal. Public Health Nutr. 2009 Jul;12(7):922-931.

8. Cheng Y, Dibley MJ, Zhang X, Zeng L, Yan $H$. Assessment of dietary intake among pregnant women in a rural area of western China. BMC Public Health. 2009 Jul 9;9:222.

9. Erkkola M, Karppinen M, Järvinen A, Knip M, Virtanen SM. Folate, vitamin D, and iron intakes are low among pregnant Finnish women. Eur J Clin Nutr. 1998 Oct:52(10):742-748.

10. Baer HJ, Blum RE, Rockett HR, Leppert J, Gardner JD, Suitor CW, Colditz GA. Use of a food frequency questionnaire in American Indian and Caucasian pregnant women: a validation study. BMC Public Health. 2005 Dec 15;5:135.

11. Rogers I, Emmett P, Baker D, Golding J. Financial difficulties, smoking habits, composition of the diet and birthweight in a population of pregnant women in the South West of England. ALSPAC Study Team. Avon Longitudinal Study of Pregnancy and Childhood. Eur J Clin Nutr. 1998 Apr;52(4):251-260.

12. Fazio Ede S, Nomura RM, Dias MC, Zugaib $M$. Dietary intake of pregnant women and maternal weight gain after nutritional counseling. Rev Bras Ginecol Obstet. 2011 Feb;33(2):87-92.

13. Paknahad Z, Fallah A, Moravejolahkami AR. Maternal Dietary Patterns and Their Association with Pregnancy Outcomes. Clin Nutr Res. 2019 Jan 25;8(1):64-73.

14. Chia AR, Chen LW, Lai JS, Wong CH, Neelakantan N, van Dam RM, Chong MF. Maternal Dietary Patterns and Birth Outcomes: A Systematic Review and Meta-Analysis. Adv Nutr. 2019 Jul 1;10(4):685-695.

Conflict of interest: none declared Financial support: none declared 